\title{
O.V. Sinyavskaya
}

Institute for Social Policy, National Research University - Higher School of Economics

Moscow, Russia

S.S. Biryukova

Institute for Social Policy, National Research University - Higher School of Economics

Moscow, Russia

\section{Possible Measures Aimed at Reducing Informal Employment and Hidden Wages}

Abstract. The scale of informal employment and hidden wages in Russia is significant and has increased even under conditions of economic growth and tax reforms throughout the 2000s. International experience proves that success in reducing the level of informal employment can only be achieved by implementing a comprehensive policy that combines incentives and sanctions in various spheres of regulation and includes broader tasks for improving institutions, economic reforms, and changing social norms related to relevance of informal relations. Within the framework of the study, based on an analysis of the specifics and causes of the existence of informal and shadow employment in Russia, authors formulate recommendations aimed at reducing informal employment and hidden wages. Recommendations take into account relevant international experience, as well as the specifics of the causes of informal employment in Russia and policies already undertaken by the Russian government.

Keywords: informal employment, shadow employment, hidden wages, tax regulation, economic regulation. JEL Classification: J46, J48.

\section{E.T. Гурвич}

Экономическая экспертная группа, НИФИ, Москва

Журнал НЭА,

Е.С. Вакуленко

НИУ ВШЭ, Москва

\section{Исследования российского рынка труда и экономическая политика}

Аннотация. В статье обобщаются результаты работ, посвященных изучению механизмов российского рынка труда. Рассматривается формирование безработицы и оплаты труда, связь показателей рынка труда с инфляцией и адаптация рынка труда к шокам. Показано, что российский рынок труда отличается высокой гибкостью, о чем свидетельствует, в частности, последовательное снижение естественного уровня безработицы (NAIRU), большая эластичность реальной заработной платы по безработице и быстрое восстановление полной занятости после негативных внешних шоков. Выделены проблемы на российском рынке труда, которые в ближайшие годы могут стать важнейшим ограничением экономического роста (в частности, сокращение численности рабочей силы и рост доли оплаты труда в ВВП), если не будут приняты действенные меры, опирающиеся на результаты ранее проведенных и новых научных исследований.

Ключевые слова: российская экономика, рынок труда, гибкость реальной заработной платы, адаптаиия к шокам.

Классификация JEL: E24, J08, O57.

\section{Формирование безработицы}

Значительную часть показателей, играющих ключевую роль при формировании макроэкономической политики, составляют различные характеристики рынка труда - прежде всего безработица и заработная плата.

\footnotetext{
The work, some of the results of which are presented in this article, was carried out within the framework of the project "Development of the system of public finances of the Russian Federation", implemented by the order of the Ministry of Finance of Russia.
} 
Соответственно проведение такой политики требует детального изучения механизмов рынка труда - как формируются описывающие его состояние переменные, каким образом они связаны между собой и с другими агрегированными показателями экономики. При этом речь идет не только о количественных параметрах, но и о качественных характеристиках взаимного влияния, включая направление причинно-следственных связей между различными показателями, выделение краткои долгосрочных связей, скорость возвращения рынка труда к долгосрочной динамике (при ее наличии) и т.д.

Одно из базовых понятий здесь составляет «естественный уровень безработицы», или используемый в последнее время термин «безработица, не ускоряющая инфляцию» (NAIRU). Оценки этого показателя, полученные разными авторами, заметно различаются. Так, авторы (Брагин, Осаковский, 2004; Гафаров, 2011) получили значения NAIRU, близкие к $8 \%$, а авторы (Ахундова, Коровкин, 2006) пришли к выводу, что NAIRU уменьшался с 8,7\% в 1999 г. до 5,6\% в конце 2004 г. Последние оценки приведены в работе (Sanjani, 2017), где показано, что уровень NAIRU в последние годы последовательно снижался (с 7,5\% в 2003 г. до 5,5\% в 2016 г.). Автор связывает такую динамику с повышением гибкости российского рынка труда. При этом в последние годы процесс снижения NAIRU замедлился примерно до 0,1 процентного пункта (п.п.) в год. Иными словами, дальнейшее снижение «естественого уровня безработицы» может слегка смягчить, но не компенсировать последствия сокращения численности рабочей силы.

Следующий важный вопрос - взаимосвязь между показателями производства и безработицы (или занятости). Классическую форму описания соотношения между этими переменными дает закон Оукена (3О). Для формирующихся рынков, включая Россию, используется форма 3О, связывающая изменение безработицы и производства:

$$
u_{t}-u_{t-1}=a+b g_{t}+\varepsilon_{t},
$$

где $u$ - уровень безработицы, $g-$ темп роста ВВП, $b$ - коэффициент Оукена. Данное соот- ношение показывает, как реагирует безработица на отклонения производства от долгосрочного тренда в рамках бизнес-цикла. В принципе рынок труда может адаптироваться к шокам производства по нескольким каналам: за счет изменения уровня экономической активности, уровня безработицы, среднего числа часов, отработанных работником, и производительности труда (определяемой отношением ВВП к числу занятых). Закон Оукена утверждает, что доля адаптации, происходящая за счет изменения безработицы, является устойчивой (по крайней мере для каждой страны) - именно эту долю и показывает коэффициент Оукена. Соотношение (1) дает также возможные темпы роста экономики $g$ при неизменных показателях рынка труда (безработицы, уровня экономической активности, среднего числа отработанных часов) они определяются формулой $g=-a / b$. Такой автономный темп роста можно интерпретировать как средний темп роста производительности труда за счет научно-технического прогресса, повышения качества человеческого капитала и т.д.

Стандартная оценка соотношения (1) показала наличие значимой краткосрочной связи со значением коэффициента Оукена -0,103 (Вакуленко, Гурвич, 2015а). Иными словами, краткосрочная реакция рынка труда на ускорение роста экономики на 1 п.п. означает дополнительное снижение безработицы на 0,1 п.п. Показатели изменения безработицы и роста ВВП оказались связаны также долгосрочным соотношением (коинтегрированы). В долгосрочной перспективе увеличение ВВП на $1 \%$ связано со снижением безработицы на 0,07-0,08 п.п. Эластичность численности занятых по ВВП составляет 0,16-0,18 (Вакуленко, Гурвич, 2015а). Оценки коэффициента $a$ в уравнении (1) имеют недостаточно высокую значимость, чтобы их можно было использовать для оценки потенциала долгосрочного роста российского ВВП.

Связь безработицы с темпами роста ВВП нередко имеет асимметричный характер, отличаясь для периодов роста и спада. Здесь возможны два объяснения: избежание рисков 
и удержание работников. В первом случае, как только начинается рецессия, работодатели сокращают издержки, в том числе на оплату труда, чтобы избежать убытков. Второй вариант предполагает, что увольнение и набор работников имеют законодательные ограничения либо сопряжены с дополнительными издержками (на выплату выходных пособий, поиски, отбор и обучение работников и т.д.). Тогда, напротив, при ухудшении конъюнктуры работодатели пытаются удержать работников. Для развитых стран типична более сильная реакция при спаде, т.е. избежание рисков. Анализ асимметричности связей на российском рынке труда показал, что реакция на негативные шоки производства более чем в два раза превышает силу реакции на позитивные. Таким образом, в поведении работодателей в России (как и в большинстве других стран) преобладает уход от рисков, а не стремление сохранить работников.

Имеющиеся оценки свидетельствуют о том, что в нашей стране адаптация к падению производства лишь в небольшой степени происходит за счет роста безработицы. Однако это типично не только для России - как показывают (Вакуленко, Гурвич, 2015а), близкие значения коэффициента Оукена имеют такие страны, как Германия, Нидерланды, Бразилия, а для Италии оценка данного коэффициента оказывается даже меньшей по абсолютной величине.

Найденная взаимосвязь между показателями занятости/безработицы и ВВП потенциально имеет разные интерпретации: она может отражать тот факт, что использование дополнительной рабочей силы увеличивает объем производства (как это предусматривают производственные функции), либо - что расширение производства создает дополнительный спрос на рабочую силу. В ЮАР направление причинности в долгосрочной перспективе идет от безработицы к ВВП, а в Малайзии связь между рассматриваемыми переменными имеет двусторонний характер (Noor et al., 2007). Применительно к России (Вакуленко, Гурвич, 2015а) показали, что причинно-следственные связи направлены от производства к безрабо- тице, т.е. за законом Оукена в нашей стране стоит изменение спроса на труд.

Построенные оценки закона Оукена позволяют ответить на важный вопрос, который часто оказывается в центре внимания не только экономистов, но и политиков, будет ли ожидаемый рост экономики сопровождаться увеличением числа рабочих мест. Ответ здесь далеко не очевиден. С одной стороны, рост выпуска подразумевает повышение эффективности производства, что может сокращать спрос на труд при данном объеме выпуска. С другой стороны, связанное с этим снижение издержек увеличивает производство, стимулируя тем самым расширение спроса на труд. Как показал (Gali, 1996), характер связи определяется в данном случае источником роста экономики. Если он обусловлен технологическим прогрессом, то повышение производительности труда сопровождается снижением занятости. Напротив, если рост происходит за счет расширения агрегированного спроса, то он увеличивает спрос на труд.

Положительная связь между производством и занятостью, найденная для России, указывает на то, что достаточно интенсивный рост ВВП сопровождается снижением безработицы (что и наблюдалось в период с 2000 по 2012 г.). Это подтверждает вывод (Кудрин, Гурвич, 2014) о том, что основным источником роста российской экономики в период после 2000 г. служило расширение спроса, а не технологический прогресс.

Экономический рост без новых рабочих мест вызывает серьезную озабоченность в странах с высокой безработицей. Россия на нынешнем этапе сталкивается с противоположной ситуацией: сравнительно низкий текущий уровень безработицы сочетается с прогнозируемым сокращением численности населения в трудоспособном возрасте. По оценкам (Иванова и др., 2017), в период до 2030 г. численность рабочей силы будет снижаться в среднем на 0,5-0,6\% в год. Можно с уверенностью утверждать, что эта тенденция (если не начнет действовать новая модель роста) будет серьезно ограничивать будущую динамику российской экономики. 


\section{Формирование заработной платы}

Простейший анализ показывает, что в условиях рынка заработная плата должна соответствовать предельной производительности труда. Эмпирические данные подтверждают наличие тесной долгосрочной связи между динамикой производительности и оплаты труда в большинстве стран (Meager, Speckesser, 2011). Вместе с тем производительность - не единственный фактор, определяющий оплату труда, она существенно зависит также от уровня безработицы. Согласно оценкам, полученным (Вакуленко, Гурвич, 2015b) для известной модели, увязывающей между собой все три отмеченных выше показателя, рост производительности труда на $1 \%$ ведет в России к росту реальной заработной платы на $0,59 \%$ (или на $0,73 \%$, если говорить не о заработной плате, а о показателе оплаты труда, рассчитанном по системе национальных счетов). Сила полученной связи типична для других стран. Близкие значения связи были получены для двух панелей, одна из которых включала 13 стран зоны евро, а другая - 19 формирующихся рынков (Вакуленко, Гурвич, 2015b).

Полученные в том же исследовании оценки показали, что снижение безработицы на 1 п.п. при прочих равных повышает реальную заработную плату на $12-14 \%$.

Отметим, что среди части экономистов достаточно популярна концепция «эффективной заработной платы» (efficiency wages), согласно которой работодатели могут устанавливать заработную плату на уровне выше, чем диктуется фактической производительностью работников, в надежде, что высокая оплата будет стимулировать трудовые усилия работников, тем самым окупив дополнительные издержки на труд. Данная концепция, как и традиционная, также предусматривает положительную связь между оплатой труда и его производительностью, однако содержание взаимосвязи оказывается иным: направление влияния идет от заработной платы к производительности. Механизм әффективной заработной платы (если получает подтверждение) дает новое объяснение структурной безработицы, альтернативное обычным представлениям о ригидности рынка труда как ее основном источнике (Ehrenberg, Smith, 2012). В работе (Dohmen et al., 2014) авторы интерпретировали полученные ими результаты исследований на микроуровне как косвенное подтверждение актуальности этой гипотезы для России.

Анализ в (Вакуленко, Гурвич, 2015b) показал, что в России связь между производительностью труда и реальной величиной заработной платы имеет явно выраженное направление от первого показателя ко второму. Это позволяет отвергнуть возможность действия в России механизма эффективной заработной платы.

При изучении рынка труда необходимо учитывать, что он состоит из связанных между собой сегментов, имеющих существенные особенности. В первую очередь это относится к разделению на сектор, финансируемый из бюджета, и остальную часть (небюджетный, или частный, сектор). В работах (Gimpelson, Lukiyanova, 2009; Шарунина, 2013) изучалось соотношение между оплатой труда в этих секторах, однако не меньшее значение имеет связь между изменением заработной платы в бюджетном и частном секторах.

В (Иванова, 2015) показано наличие тесной связи между динамикой заработной платы в этих секторах. Этот вывод ставит вопрос о направлении влияния, являются ли первичными изменения оплаты в бюджетном или в частном секторе. Проведенный анализ показал, что лидером в процессе установления заработной платы в долгосрочном периоде выступает частный сектор. В краткосрочном периоде, в отличие от долгосрочного, лидером в процессе установления заработной платы выступает государственный сектор. Такая ситуация согласуется с результатами как теоретических работ, так и эмпирических исследований, выполненных для других стран.

Важный вывод для формирования экономической политики состоит в том, что при принятии решений о повышении заработной платы в бюджетном секторе необходимо тщательно изучать вероятные последствия для частного сектора. Прежде всего необходимо оценивать вынужденный рост оплаты труда 
в частном секторе и его влияние на конкурентоспособность российской экономики, инфляцию, занятость и т.д.

Важнейшей интегральной характеристикой механизмов формирования заработной платы в стране служит доля оплаты труда в ВВП и ее динамика. Долгое время считалось, что данный показатель, определяемый, с одной стороны, соотношением производительности труда и капитала, а с другой - силой переговорных позиций работников и работодателей, достаточно стабилен. Однако в последнее время ситуация изменилась, причем ситуация в России в этом отношении кардинально отличается от ситуации в большей части других стран. Расчетные значения доли оплаты труда в ВВП (приведенные к сопоставимому виду, для того чтобы учесть изменение методики Росстата после 2011 г.) показывают, что в России она выросла с $40 \%$ в 2000 г. до $54 \%$ в 2016 г. (рис. 1). Для других стран этот показатель был стабильным (в странах еврозоны) либо имел понижательный тренд (в США или Польше). Еще одно исключение составляет Бразилия, однако там рост выражен существенно слабее, чем в нашей стране.

Авторы (Вакуленко, Гурвич, 2015b) дали объяснение аномальной динамики доли оплаты труда: в условиях, когда эластичность оплаты труда по его производительности существенно меньше единицы, удельный вес труда в ВВП, на первый взгляд, не должен расти.

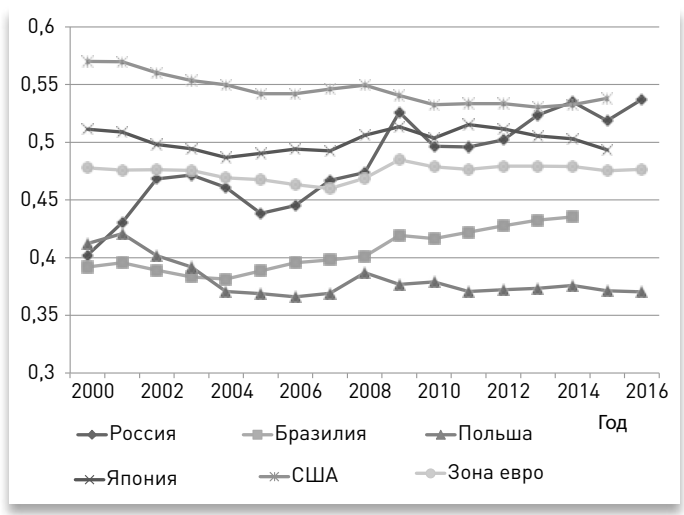

Рис. 1

Расчетная доля оплать труда в ВВП, \%

Источник: расчеты авторов по данным ОЭСР и Росстата.
Однако параллельно существенно снизилась безработица, что дополнительно повышало заработную плату. В последние три года доля оплаты труда в ВВП стабилизировалась (как это было и в 2008 г.), однако в случае ускорения экономического роста без изменения его модели доля оплаты труда вновь начнет повышаться. Это приведет к дальнейшему сокращению рентабельности производства, а также объема собственных средств компаний, составляющих основной источник финансирования инвестиций. В целом эти два эффекта накладывают жесткие ограничения на реально достижимые темпы роста ВВП.

\section{Показатели рынка труда и инфляция}

Фундаментальная связь между инфляцией и безработицей описывается кривой Филлипса. Это соотношение изучалось в работах (Брагин, Осаковский, 2004; Гафаров, 2011; Соколова, 2014; и др.). В (Sanjani, 2017), где анализ уже захватывает период использования инфляционного таргетирования, строится гибридная неокейнсианская кривая Филлипса с изменяющимися во времени коэффициентами. Она достаточно хорошо описывает динамику инфляции (за исключением отдельных эпизодов резкого повышения цен). Отмечается, что построенная кривая Филлипса имеет более крутой наклон, чем для большинства стран с формирующимся рынком, т.е. инфляция сильнее реагирует на снижение безработицы. При этом отмечается, что наклон кривой Филлипса для России будет возрастать по мере возврата экономики к устойчивому росту. Один из выводов из проведенного анализа состоит в том, что Центральному банку РФ следует быть готовым прилагать дополнительные усилия при снижении инфляции ниже ее естественного уровня.

Механизм формирования кривой Филлипса включает в качестве звеньев, во-первых, отмеченную выше обратную зависимость реальной заработной платы от безработицы и, во-вторых, взаимосвязь между номинальной заработной платой и ценами. Согласно модели инфляции издержек, рост оплаты труда увеличивает себестоимость про- 
дукции и тем самым приводит к росту цен. В рамках модели инфляции спроса причинноследственная связь действует в обратном направлении: изменение инфляции дает основания для изменения заработной платы в экономике. Для развитых стран (например, США) характерна лишь односторонняя связь - от инфляции к заработной плате, что соответствует выводам модели инфляции спроса.

В (Иванова, 2016) показано, что в России связь между инфляцией и заработной платой имеет двусторонний характер, т.е. одновременно действуют и модель инфляции издержек, и модель инфляции спроса. Такая ситуация потенциально создает риск возникновения классической инфляционной спирали. Международный опыт показывает, что инфляционное таргетирование, применяемое Банком России с конца 2014 г., не только обеспечивает замедление инфляции, но и изменяет ее механизмы, в том числе способствует переходу к модели инфляции спроса.

\section{Адаптация к шокам}

Межстрановой анализ, проведенный по итогам Великой рецессии (международного финансового кризиса 2007-2008 гг.) (Aiginger, Horvath, Mahringer, 2012; Eichhorst, Feil, Marx, 2010; и др.), позволил сделать несколько важных выводов, часть из которых касается механизмов рынка труда.

1. Чем более гибким был рынок труда в момент кризиса, тем менее болезненными оказались последствия внешних шоков.

2. Гибкость рынка труда обеспечивала также более быстрое восстановление состояния полной занятости (т.е. возвращение безработицы к ее естественному уровню).

3. Реакция рынка труда на шоки в кризисный период может отличаться от той, которую можно было бы ожидать на основе его поведения в спокойное время в силу уникальных масштабов и природы шоков, а также принимаемых правительством специальных антикризисных программ.
В качестве меры гибкости рынка труда большинство исследований использует уровень ограничений на действия работодателей. Авторы (Artha, Haan, 2011) показали, что чем меньшие издержки (в самом широком смысле слова) несет бизнес при найме работников, тем меньшими (при прочих равных) оказываются потери ВВП при кризисе. В свою очередь, (Aiginger, Horvath, Mahringer, 2012) нашли, что регуляторное бремя, испытываемое рынком труда, повышает удельное (т.е. рассчитанное на единицу спада производства) сокращение занятости при кризисе.

Основным макроэкономическим показателем, характеризующим способность рынка труда быстро и эффективно адаптироваться к кризису, служит эластичность реальной заработной платы по безработице. Согласно (Blanchard, 2006) высокая эластичность реальной заработной платы свидетельствует о том, что действие рыночных механизмов не связано избыточными регуляторными ограничениями, благодаря чему рынок труда быстро восстанавливает равновесие. Различия между странами - в способности рынка труда адаптироваться - хорошо иллюстрирует рис. 2. ОН показывает, что в таких странах, как Россия или США, кризис приводит к сравнительно недолгому повышению безработицы, после чего ее уровень возвращается к прежним значениям. В Испании ситуация оказалась противоположной: после кризиса безработица резко (более чем втрое) выросла, а затем крайне медленно возвращается к прежнему равновесию (через девять лет ее уровень все еще в 2,5 раза выше докризисного). Наконец, во Франции рост безработицы оказался не столь значимым, однако нет признаков ее возвращения на докризисные рубежи.

Неспособность рынка труда адаптироваться к шокам (его ригидность) имеет институциональные корни в виде ограничений на прием и увольнение работников, установление и изменение заработной платы и т.п. На макроэкономическом уровне негибкость рынка труда проявляется в низкой эластичности реальной заработной платы по безработице. Ряд авторов показал, что указанные 


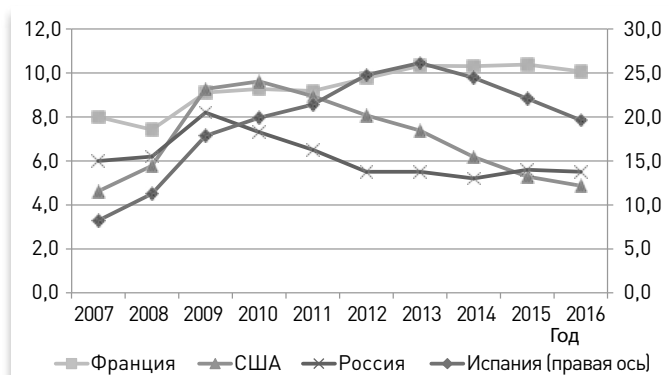

Pис. 2

Динамика уровня безработичы после Великой речессии, \%

Источник: данные ОЭСР и Росстата.

аспекты ригидности тесно связаны между собой. Так, согласно (Babetský, Dybczak, 2012) широкое распространение в стране профсоюзов (характеризуется долей работников, включенных в коллективные соглашения с работодателями) или жесткость законодательной защиты работников существенно снижают эластичность реальной заработной платы по безработице.

Авторы (Вакуленко, Гурвич, 2016) провели сравнительный анализ гибкости российского рынка труда, используя три различные спецификации модели, описывающей связь между реальной заработной платой и безработицей. Независимо от способа оценки эластичность реальной заработной платы по уровню безработицы для России оказывается выше (по абсолютной величине), чем во всех или почти всех других странах, для которых имеются аналогичные оценки. Это позволяет с уверенностью заключить, что российский рынок труда характеризуется очень высокой гибкостью. Полученный результат вполне согласуется с динамикой безработицы, наблюдавшейся после Великой рецессии 2008-2009 гг. и в ходе финансового кризиса, начавшегося во втором полугодии 2014 г. В обоих случаях уровень безработицы достаточно быстро вернулся к прежним (или близким к ним) значениям.

\section{Заключение}

Обобщая проведенный анализ, можно сделать вывод о том, что российский рынок труда в целом демонстрирует высокую гиб- кость и способность адаптироваться к шокам. В результате расчетный уровень естественной безработицы последовательно снижается, а фактическая безработица находится на устойчиво низком уровне. Это означает, что государство в целом не создает существенных искажений в поведении работодателей и работников. Вместе с тем некоторые решения последних лет (такие как резкое повышение заработной платы в образовании и здравоохранении, согласно майским указам Президента РФ от 2012 г., или столь же резкое повышение минимальной зарплаты в 2018 г.) могут иметь негативные последствия для рынка труда.

Экономической политике в ближайшие годы предстоит выработать решения нескольких связанных между собой острых проблем, с которыми столкнется российский рынок труда. Во-первых, увеличившаяся доля оплаты труда в ВВП снизила конкурентоспособность российской әкономики и сократила валовую прибыль, служащую главным источником инвестиционных ресурсов. Во-вторых, расчеты, основанные на демографических прогнозах, показывают, что наша страна вступила в длительный период быстрого сокращения численности рабочей силы. Поскольку уровень безработицы уже опустился ниже своего естественного уровня, а гибкость реальной заработной платы по безработице в нашей стране рекордно велика, ситуация на рынке труда грозит серьезно затормозить будущий рост производства, если не будут приняты самые энергичные меры.

Таким образом, процессы, происходящие на рынке труда, в предстоящий период будут иметь ключевое значение с точки зрения общих перспектив российской экономики. Успех во многом будет зависеть от того, насколько решение перечисленных проблем будет опираться на накопленные и новые результаты научных исследований.

\section{ЛИТЕРАТУРА}

Ахундова О.В., Коровкин А.Г. (2006). Опыт оценки естественного уровня безработицы в экономике России. В сб.: «Науч- 
ные труды: Институт народнохозяйственного прогнозирования РАН». С. 488-508.

Брагин В., Осаковский В. (2004). Оценка естественного уровня безработицы в России в 1994-2003 гг.: эмпирический анализ // Вопросъ экономики. № 3. C. 95-104.

Вакуленко Е.С., Гурвич Е.Т. (2015а). Взаимосвязь ВВП, безработицы и занятости: углубленный анализ закона Оукена для России // Вопросъ экономики. № 3. С. 5-27.

Вакуленко Е.С., Гурвич Е.Т. (2015b). Моделирование механизмов российского рынка труда // Вопросъ экономики. № 11. С. 1-25.

Вакуленко Е.С., Гурвич Е.Т. (2016). Гибкость реальной заработной платы в России: сравнительный анализ // Журнал Новой экономической ассочиаиии. № 3 (31). C. 67-92.

Гафаров Б.Н. (2011). Кривая Филлипса и становление рынка труда в России // Экономический журнал Высшей школь экономики. № 2. С. 155-176.

Иванова М. (2016). Анализ характера причинно-следственной связи между инфляцией и заработной платой в России // Проблемь прогнозирования. № 5 (158). С. 119-132.

Иванова М.А. (2015). Взаимосвязь заработной платы в частном и государственном секторах // Вопросъ экономики. № 7. C. 120-141.

Иванова М., Балаев А., Гурвич Е. (2017). Повышение пенсионного возраста и рынок труда // Вопросъ экономики. № 3. С. 22-39.

Кудрин А., Гурвич Е. (2014). Новая модель роста для российской экономики // Вопросы экономики. № 12. С. 4-36.

Соколова А.В. (2014). Инфляционные ожидания и кривая Филлипса: оценка на российских данных // Денъги и кредит. № 11. С. $61-67$.

Шарунина А.В. (2013). Является ли российский «бюджетник» «неудачником»? Анализ межсекторных различий в оплате труда // Экономический журнал Высшей школь экономики. № 17 (1). С. 75-107.

Aiginger K., Horvath G., Mahringer H. (2012). Why Labor Market Response Differed in the Great Recession: The Impact of Institutions and Policy // DANUBE: Law and Economics Review. Issue 3. P. 1-19.

Artha I., Haan J. de (2011). Labor Market Flexibility and the Impact of the Financial Crisis // Kyklos. Vol. 64. Issue 2. P. 213-230.

Babecký J., Dybczak K. (2012). Real Wage Flexibility in the European Union: New Evidence from the Labour Cost Data. Czech National Bank. Working Paper 1.

Blanchard O. (2006). European Unemployment: The Evolution of Facts and Ideas // Economic Policy. Vol. 45 (21). P. 5-59.

Dohmen T., Lehmann H., Schaffer M. (2014). Wage Policies of a Russian Firm and the Financial Crisis of 1998: Evidence from Personnel Data - 1997 to 2002 // Indus trial and Labor Relations Review. Vol. 67 (2). P. 504-531.

Ehrenberg R.G., Smith R.S. (2012). Modern Labor Economics: Theory and Public Policy. 11th Edition. Prentice Hall.

Eichhorst W., Feil M., Marx P. (2010). Crisis, What Crisis? Patterns of Adaptation in European Labor Markets. IZA Discussion Paper No. 5045. P.1-33.

Gali J. (1996). Technology, Employment, and the Business Cycle: Do Technology Shocks Explain Aggregate Fluctuations? NBER Working Paper No. 5721.

Gimpelson V., Lukiyanova A. (2009). Are Public Sector Workers Underpaid in Russia? Estimating the Public-Private Wage Gap. IZA Discussion Paper No. 394.

Meager N., Speckesser S. (2011). Wages, Productivity and Employment: A Review of Theory and International Data // European Employment Observatory. October. P. 1-73.

Noor Z., Nor N., Ghani J. (2007). The Relationship between Output and Unemployment in Malaysia: Does Okun's Law Exist? // International Journal of Economics and Management. Vol. 1 (3). P. 337-344. 
Sanjani M.T. (2017). Putting the Curve Back in Russia's Phillips Curve: A Time Varying Approach. IMF Country Report No. $17 / 198$. P. 78-93.

Поступила в редакиию 9 февраля 2018 года

\section{REFERENCES}

(with English translation or transliteration)

Aiginger K., Horvath G., Mahringer H. (2012). Why Labor Market Response Differed in the Great Recession: The Impact of Institutions and Policy. DANUBE: Law and Economics Review, 3, 1-19.

Akhundova O.V., Korovkin A.G. (2006). An Attempt to Estimate the Natural Rate of Unemployment in the Russian Economy. In: "Scientific Articles-Institute of Economic Forecasting Russian Academy of Sciences", 488-508 (in Russian).

Artha I., Haan J. de (2011). Labor Market Flexibility and the Impact of the Financial Crisis. Kyklos, 64, 2, 213-230.

Babecký J., Dybczak K. (2012). Real Wage Flexibility in the European Union: New Evidence from the Labour Cost Data. Czech National Bank. Working Paper 1.

Blanchard O. (2006). European Unemployment: The Evolution of Facts and Ideas. Economic Policy, 45 (21), 5-59.

Bragin V., Osakovsky V. (2004). Estimation of the Natural Rate of Unemployment in Russia in 1994-2003: An Empirical Analysis. Voprosy Economiki, 3, 95-104 (in Russian).

Dohmen T., Lehmann H., Schaffer M. (2014). Wage Policies of a Russian Firm and the Financial Crisis of 1998: Evidence from Personnel Data - 1997 to 2002. Industrial and Labor Relations Review, 67 (2), 504-531.

Ehrenberg R.G., Smith R.S. (2012). Modern Labor Economics: Theory and Public Policy. 11th Edition, Prentice Hall.

Eichhorst W., Feil M., Marx P. (2010). Crisis, What Crisis? Patterns of Adaptation in European Labor Markets. IZA Discussion Paper No. 5045, 1-33.
Gafarov B. (2011). Phillips Curve and the Labor Market Formation in Russia. The HSE Economic Journal, 2, 155-176 (in Russian).

Gali J. (1996). Technology, Employment, and the Business Cycle: Do Technology Shocks Explain Aggregate Fluctuations? NBER Working Paper No. 5721.

Gimpelson V., Lukiyanova A. (2009). Are Public Sector Workers Underpaid in Russia? Estimating the Public-Private Wage Gap. IZA Discussion Paper No. 394.

Ivanova M. (2016). Analysis of the Nature of Cause-and-Effect Relationship between Inflation and Wage in Russia. Studies on Russian Economic Development, 27 (5), 575584 (in Russian).

Ivanova M., Balaev A., Gurvich E. (2017). Implications of Higher Retirement Age for the Labor Market. Voprosy Economiki, 3, 22-39 (in Russian).

Ivanova M.A. (2015). The Interaction between Public and Private Sector Wages. Voprosy Economiki, 7, 120-141.

Kudrin A., Gurvich E. (2014). A New Growth Model for the Russian Economy. Voprosy Economiki, 12, 4-36 (in Russian).

Meager N., Speckesser S. (2011). Wages, Productivity and Employment: A Review of Theory and International Data. European Employment Observatory, October, $1-73$.

Noor Z., Nor N., Ghani J. (2007). The Relationship between Output and Unemployment in Malaysia: Does Okun's Law Exist? International Journal of Economics and Management, 1 (3), 337-344.

Sanjani M.T. (2017). Putting the Curve Back in Russia's Phillips Curve: A Time Varying Approach. IMF Country Report No. 17/198, 78-93.

Sharunina A.V. (2013). Are Public Sector Workers "Losers"? Estimation of the Public-private Wage Gap in Russia. The HSE Economic Journal, 17 (1), 75-107 (in Russian).

Sokolova A.V. (2014). Inflation Expectations and the Phillips Curve: Assessment Based on Russian Data. Money and Credit, 11, 61-67 (in Russian). 
Vakulenko E., Gurvich E. (2015a). The Relationship of GDP, Unemployment Rate and Employment: In-Depth Analysis of Okun's Law for Russia. Voprosy Economiki, 3, 5-27 (in Russian).

Vakulenko E., Gurvich E. (2015b). Modeling the Mechanism of Russian Labor Market. Voprosy Economiki, 11, 1-25 (in Russian). Vakulenko E., Gurvich E. (2016). Real Wage Flexibility in Russia: Comparative Analysis. Journal of the New Economic Association, 3 (31), 67-92 (in Russian).

Received 2.02.2018

\section{E.T. Gurvich}

Economic Expert Group, Financial Research Institute, Moscow, Russia

E.S. Vakulenko

National Research University Higher School of Economics, Moscow, Russia

\section{Studies of Russian Labor Market and Economic Policy}

Abstract. The paper summarizes the studies on the mechanisms of Russian labor market. The subjects under consideration include unemployment and wages formation, relationship between key labor market variables and inflation, and labor market adjustment to negative shocks. We demonstrate that the general feature of Russian labor market is its high flexibility, which shows itself a gradual decline of the NAIRU level, high elasticity of real wages by unemployment rate, rapid return to full employment after negative external shocks. Problems rooted in the labor market are specified (primarily declining labor supply and increasing labor share in GDP), their neglect can become a major impediment for economic growth if forceful measures based on the earlier and future research findings are not taken.

Keywords: Russian economy, labor market, real wage flexibility adjustment to shocks.

JEL Classification: E24, J08, O57. 